\title{
Learning from an exceptional boy
}

\author{
Hannah R Cock ${ }^{1,2}$
}

- Additional material is published online only. To view please visit the journal online (http://dx.doi.org/10.1136/ practneurol-2017-001853)

${ }^{1}$ Atkinson Morley Regional Epilepsy Network, St George's University Hospitals NHS Foundation Trust, London, UK ${ }^{2}$ Institute of Medical \& Biomedical Education, St George's University, London, UK

\section{Correspondence to} Professor Hannah R Cock, Atkinson Morley Regional Epilepsy Network, St George's University Hospitals NHS Foundation Trust, London SW17 OQT,UK; hannahrc@sgul.ac.uk

Accepted 20 December 2017 Published Online First

1 February 2018
Check for updates

To cite: Cock HR. Pract Neurol 2018;18:170171.
My son, Alfie, was born 6 years into my role as an academic consultant neurologist with an interest in epilepsy. On his second day he was floppier than expected, and so was referred for a brain scan that revealed multiple malformations, the cause of which was never determined. He had his first seizure at 3 months of age, evolving into a clear developmental epileptic encephalopathy within weeks. By age 18 months he had specialist seating, PEG feeds, a tracheostomy, home oxygen and was ventilator-assisted. He was multisensory impaired, and had very little trunk or head control ever, though on a good day could kick and hit out at noisy toys with some purpose. He smiled, laughed, loved swimming, tasters and cuddles, and knew those most familiar to him (figures 1 and 2). Alfie far outlived initial expectations, but died after a short illness in April 2016, leaving a legacy through organ donation, through the many lives he touched, and through all that I learnt from him (supplementary data).

If you have a chronic, life-threatening or life-limiting condition, particularly if it is unpredictable as with epilepsy, knowing there is an accessible healthcare professional in whose expertise you can have complete faith is invaluable. Alfie had an army, for which we are ever grateful. Strong advocacy is essential-to navigate the bureaucracy of benefits, health and education welfare plans-and to challenge

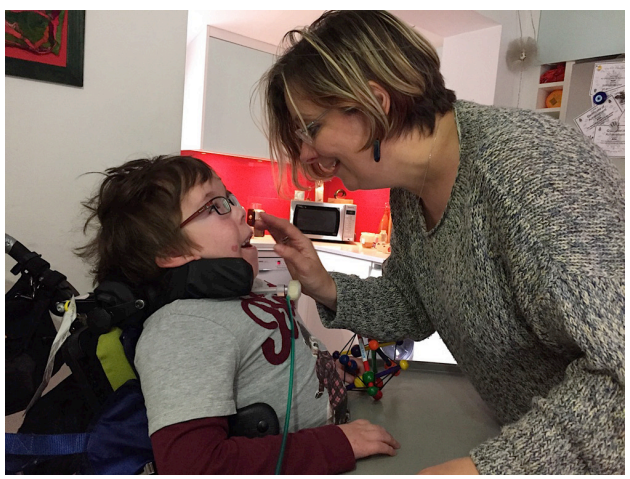

Figure 1 Alfie and I enjoying tasters on my birthday in September 2015.

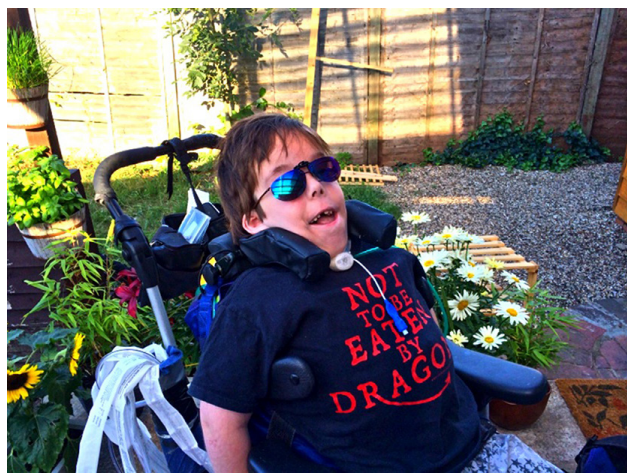

Figure 2 Alfie enjoying a visit to friends in August 2014.

those rules that don't have an evidence base. If not for educated and articulate parents and supportive professionals, due to his tracheostomy and oxygen needs Alfie could so easily have been deprived the opportunity to continue to enjoy the weightlessness and freedom offered by a swimming pool. Healthcare professionals, prepared to challenge systems that sometimes put risk aversion above all else, can make a huge difference.

Neurologists are often faced with individuals with severe disabilities, who cannot speak for themselves, and family advocates who report a quality of life you cannot see. But remember that doctors, particularly those in hospitals, see people at their worst. People at their best can be very different; judging the lives of others can only truly be done by those who experience or share that life. That is not to say you shouldn't be honest about realistic outcomes, however poor. Most families will know when it is time to let go, but acknowledging uncertainties along the way, and sharing rather than dismissing the positives will support, not undermine this.

Epilepsy is an inherently unpredictable condition, which poses particular challenges. Living with uncertainty on a day-to-day basis significantly adds to the burden of the disease: Will this be a good or a bad day? Will this bad spell last days, weeks or indefinitely? Will the 
next drug work? How will others react, given the significant misunderstanding and stigma still associated with both epilepsy and disability? Contemporaneous documentation, seizure diaries and having treatment choices can help give a sense of control, but can distract from sometimes more meaningful outcomes, particularly in drug-resistant epilepsy. My sometimes obsessive charting of seizures against drug changes undoubtedly helped me to see where a new drug was worth sticking with, and also where hope had triumphed over reality, and I had misattributed chance association. However, over time, I also realised that the seizure counts were not what mattered to Alfie's day-to-day life-such that in later years, 'quality Alf' days became a better measure. This realisation, together with evidence supporting the value of proactively screening for adverse effects and psychiatric comorbidities, ${ }^{1}$ has reinforced to me the importance of individualising treatment goals. Especially in drug-resistant epilepsy, seizure frequency continues to be the primary end point of clinical trials but may be of little consequence to quality of life, compared with seizure severity, recovery times and adverse effects. Recent data also suggest that most of the clinical trials on which we base our treatment decisions-at least with respect to efficacy - have failed to account adequately for the natural variability of epilepsy, ${ }^{2}$ meaning that every new drug we try is effectively an $n=1$ clinical trial. With escalating drug costs, agreeing on realistic and meaningful outcomes is fundamental. Importantly in this context, asking about personality and recreational activities is easily overlooked in non-verbal or severely disabled patients, but having an insight into the life they lead, and how epilepsy fits in with that is just as important. Getting a feel for the person that might be hidden underneath the disability takes time, more than commissioners often want to fund. I cannot prove it, but think this is probably cost-effective in the long term, reducing admissions and inappropriate drug use. More importantly, it is surely what any of us would want for ourselves or for our loved ones.
Finally, Alfie taught me how important good colleagues, family and friends are in challenging circumstances. We were also lucky enough to have sufficient space and resources to accommodate easily the ridiculous volume of equipment, supplies and medication he needed, together with living in one of the better boroughs in terms of disability support and home adaptations. Don't just spare a thought for all those less fortunate than yourselves, if you have the opportunity—speak out on their behalves.

So in a nutshell, what has Alfie brought to my practice? Adapt to the individual, especially with respect to treatment goals; do not judge the life of anyone based on brief moments in clinic; long-term knowledge of the patient and continuity is both rewarding and fundamental to good care in chronic disorders, and should be encouraged; add your voice to that of the family in advocating for patients.

Contributors I am the sole contributor.

Competing interests HRC reports personal fees from Sage Pharmaceuticals Ltd, personal fees from Eisai Europe Ltd, personal fees from UCB Pharma Ltd, personal fees from European Medicines Agency, personal fees from UK Epilepsy Nurse Specialist Association, non-financial support from Special Products Ltd, grants from US NIH Institute of Neurological Disorders and Stroke, non-financial support from International League Against Epilepsy, Status Epilepticus Classification Task Force, non-financial support from International League Against Epilepsy, Epilepsy Certification (education) Task Force, outside the submitted work.

Patient consent Next of kin consent obtained.

Provenance and peer review Commissioned; externally peer reviewed. This paper was reviewed by Mike Kerr, Cardiff, UK.

(C) Article author(s) (or their employer(s) unless otherwise stated in the text of the article) 2018. All rights reserved. No commercial use is permitted unless otherwise expressly granted.

\section{REFERENCES}

1 Mula M, Cock HR. More than seizures: improving the lives of people with refractory epilepsy. Eur J Neurol 2015;22:24-30.

2 Goldenholz DM, Goldenholz SR, Moss R, et al. Does accounting for seizure frequency variability increase clinical trial power? Epilepsy Res 2017;137:145-51. 